\title{
PARAMETERS OF ORGANIZATIONAL STRUCTURE IN ENTERPRISES IN THE REPUBLIC OF MACEDONIA - SPECIFICS AND OPPORTUNITIES FOR THEIR OPTIMIZATION
}

\author{
Kiril Postolov \\ "St.Cyril and Methodius" University in Skopje, Faculty of Economics, Skopje, \\ Republic of Macedonia \\ Marija Magdinceva Sopova \\ "GoceDelcev" University in Stip, Faculty of tourism and business logistics, \\ Gevgelija, Republic of Macedonia \\ Andrijana Ristovska \\ "St.Cyril and Methodius" University in Skopje, Faculty of Economics, Skopje, \\ Republic of Macedonia
}

\begin{abstract}
This paper elaborates the issue relating to some of the organizational structure parameters in the enterprises of Republic of Macedonia's economy and makes a comparison to what is proposed by the organization theory.For that purpose, empirical research was performed on 62 enterprises of the Republic of Macedonia's economy. In that respect, the SPSS package was used for accepting or rejecting given hypotheses.

The conducted research is to provide an answer to the questions relating to the specific application of organizational structure parameters in the enterprises of Republic of Macedonia's economy.

Research results have indicated that Macedonian enterprises compared to the enterprises of the developed world and theoretical postulates related to organizational structuring present similar results in certain dimensions, as well as that there are areas which need improvements and complete changes.

Key words: setting, changes, distribution of work, span of control, organizational design.
\end{abstract}

\section{INTRODUCTION}

The main question is whether organizational structure depends on the established political and economic system which dominates the regulation of social relations in a particular country.

As expected, the enterprises functioning in the economy of the Republic of Macedonia are not exceptions from this rule.

In historical terms, during the last seven decades as of the end of World War II, enterprises in the Republic of Macedonia have met the requirements prescribed with the laws that regulate the functioning thereof, in particular regarding the method of their organization (depending on ownership) and the respective management and 
governance. Compliance with the laws has an impact on the designing of an organizational structure form which is to enable effective and efficient operations of the enterprise.

However, the question, that is in the focus of attention in this paper, is whether enterprises today, in terms of their organizational structuring, comply with the rules on:

1. impact of the type of organizational organizational environment and organizational design;

2. specialization of work and applied organizational design model;

3. established span of control and the decision-making system;

4. readiness to make organizational changes.

\section{EMPIRICAL RESEARCH OF CERTAIN ORGANIZATIONAL STRUCTURE PARAMETERS IN THE ENTERPRISES IN THE ECONOMY OF THE REPUBLIC OF MACEDONIA}

Taking into account the seven-decade development and functioning of the enterprises in the economy of the Republic of Macedonia, we consider that it is of high importance to check towards which contemporary theoretical concepts does practical organization tends, to value it, and to provide suggestions for potential corrections. Moreover, we shall have to emphasize that potential differences might occur in the relevant resulting research which, when theoretical models are screened through the practice of functioning of enterprises, are either not fully applicable or the demanding of their application might result into reduction in organizational efficiency.

Reaching of this objective is related to specific research in the practice of our enterprises, which was completed by applying the survey method and direct conversation (interview) with the managers on a specified representative sample of enterprises. On that basis, we have performed a diagnosis of current organizational models that are most frequently applied in our enterprises, the problems related to their functioning located in particular organizational functions and the impact thereof on the organizational effectiveness and efficiency.

The questions contained in the survey questionnaire have focused the research interest on perceiving of elements which, in our assessment, have a decisive impact on the creation of complete and realistic view to diagnose the organizational design of our enterprises, as follows: impact of the type of organizational environment and organizational design, specialization of work and applied organizational design model, established span of control and the decision-making system, and readiness to make organizational changes. 
Obtained research results have been statistically processed, analyzed, expressed in relative numbers and, based on them, specific qualitative assessments have been given.

Representative sample of enterprises from the Republic of Macedonia's economy was determined for the needs of the research. In doing so, account was taken so as to include enterprises that are part of different sectors of the economic activity and geographic dispersion.

Chief Managers of enterprises were taken as target group of the research. The total number of enterprises in which survey was conducted was 62 .

The first question posed within the survey questionnaire refers to the established organizational structure in the enterprise. The following answers were provided:

1. functional organizational structure - 50

2. divisional organizational structure - 10

3. other organizational structure form - 2

The following chart was constructed based on the answers to this question:

Chart 1.: Organizational design model in the enterprises of Republic of Macedonia's economy

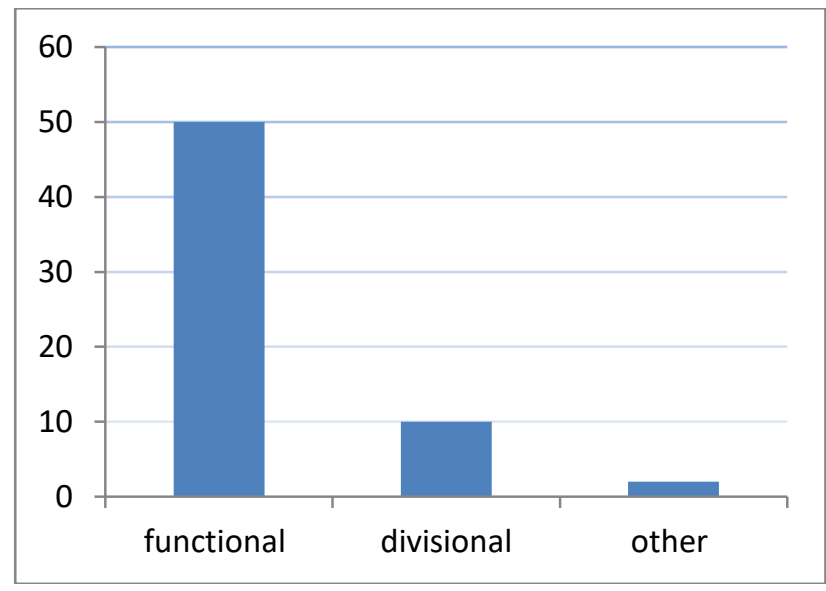

Source: Authors research

Based on the obtained empirical data, we have constructed the chart that enables us to see whether the researched situation has normal distribution: 


\section{Chart 2.: Organizational design model with constructed normal distribution}

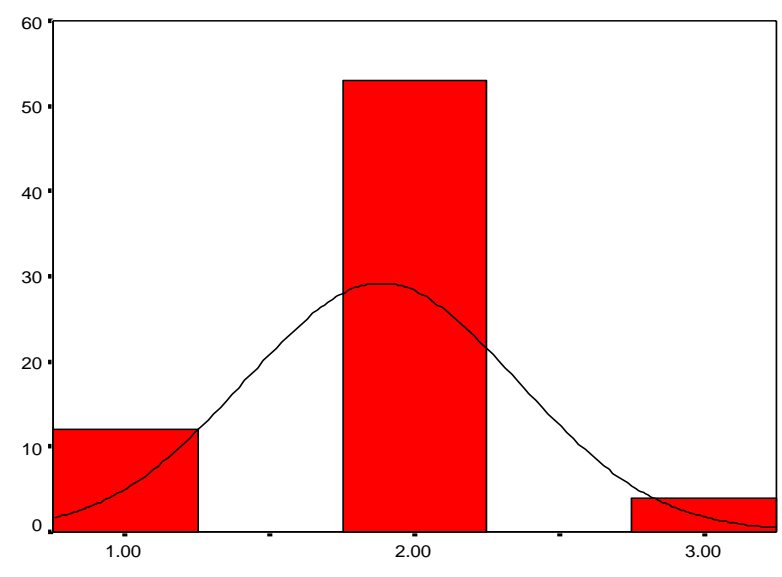

$1=$ divisional

Source: Authors research

$2=$ functional

$3=$ other

It can be concluded from the projected chart that the researched organizational structure is with normal distribution, which means that we can use the statistical tests for accepting or rejecting hypotheses, as well as for calculation of other dimensions.

The specifics of organizational environment and its impact on organizational structure is the first segment to which relevant attention is paid within the present paper (see also in Micic, 2015, Faritovna, 2014, Fang\&Chen, 2016, Rauh, 2014).

The logic for this position stems from the fact that organizational environment is the totality of "factors located outside of the enterprise which have potential impact on its operation". Organizational structure is influenced by the organizational environment. (Armstrong, 2016)

Due to the existing dependence between the environment and the organizational structure, we can test the following two hypotheses on the impact of the type of environment and the organizational structure (Pushpa, 2014):

1. If the envirnonment is homogeneous, simple, stable, then the established organizational structure is functional.

2. If the environment is heterogeneous, complex, unstable, then the established organizational structure is divisional.

Therefore, we have constructed the first question within the research paper on the impact of the organizational environment type on the organizational design. 
Parameters of organizational structure in enterprises in the Republic of Maced...

Based on the obtained answers to the survey questionnaire, we initially calculated the Pearson correlation coefficient between the type of organizational environment and organizational design of the enterprises. On the basis of empirical data, and the processing thereof, a coefficient of 0.589 was obtained with significance level of 0.01 indicating the existence of dependence level between the organizational design and the type of organizational environment.

The $\chi^{2}$ test is used for accepting or rejecting both hypotheses.

Managers were asked the question relating to the type of organizational environment in which their enterprise functions.

The following result and conclusion were obtained by conducting appropriate calculations:

- At significance level of 0.01, the critical value of the $\chi^{2}$ distribution is

two degrees of freedom lower compared to the realized value of the $\chi^{2}$

test, resulting into conclusion that the hypothesis that organizational

structure forms depend on the relevant organizational environment type

is accepted.

Theory of organization has researched that there are existing appropriate relations between specialization of work and the applied organizational model design. In order to be able to establish whether it is a rule complied with in the designing and functioning of the organizational structure in enterprises of the economy of the Republic of Macedonia, the following two hypotheses were set:

- functional organizational structure applies a high degree of work specialization

- divisional organizational structure applies low degree of work specialization (Giurge, Van Dijke \& Zheng, 2015).

In order to be able to either accept or reject the two hypotheses, the survey questionnaire included the following question to which managers should have provided an appropriate answer: enterprise?"

"What is the degree of applied work specialization in your

a) high degree of work specialization

b) low degree of work specialization

The calculations provided the following conclusions regarding the dependence of the degree of introduced work specialization and the form of the designed organizational structure:

At significance level of 0.01, the critical value of $\chi^{2}$ distribution is two degrees of freedom higher than the realized value of the $\chi^{2}$ test, resulting into conclusion that the hypothesis that organizational structure forms depend on the work specialization level is rejected. 
If we increase the level of significance to 0.05 , the final value of $\chi^{2}$ would be higher than the critical value, meaning there is a dependence between the forms of organizational structure and the degrees of specialization.

While defining the questions in this part of the questionnaire, we have appropriately given thought to the issues in regard to the span of management and the decision-making. We will explain the managers' opinions on the span of management and the system of decision-making using the responds to the following questions:

- A higher span of management is introduced in a centralized decisionmaking system;

- A lower span of management is introduced in a decentralized decisionmaking system (Ortín-Ángel \& Salas, 2002, pp. 848-876.);

After the calculations, the following conclusion concerning the interdependence of the decision-making system and the span of management was reached:

On a significance level of 0.01 the critical value of $\chi^{2}$ distribution is two degrees of freedom lower than the final value of the $\chi^{2}$ test, meaning we can accept the hypothesis of interdependence of the decision-making system and the degree of the span of management.

In regard to those reasons, based on these hypotheses, we have formed the questions from the third group:

1. Are you prepared to make the organizational changes?

2. Are you preparing your employees for the necessity for organizational changes?

3. Do you sufficiently allow your subordinates to participate in the planning and the implementation of the organizational changes?

4. Are you prepared to take the risk for the completed organizational changes?

The appropriate responses to these questions are as follows:

1. Are you prepared to make the organizational changes? $-83.87 \%$ are prepared to make organizational changes.

2. Are you preparing your employees for the necessity for organizational changes? $-80.65 \%$ of the respondents replied affirmatively.

3. Do you sufficiently allow your subordinates to participate in the planning and the implementation of the organizational changes? 70.97\% gave positive response.

4. Are you prepared to take the risk for the completed organizational changes? - A total of $93.55 \%$ of the respondents have stated that they will take the risk in case of failure to implement the organizational changes.

Our managers believe that there are numerous reasons why they think changes need to occur (see also, Basurto, 2017, Smollan, 2017, Gill\&Kleiner, 2018). 
Parameters of organizational structure in enterprises in the Republic of Maced... al., 2017):

All of those issues can be classified in these few groups (Arif et

- Organizational issues (slow decision-making process, enterprise function, low efficiency in task completion and management, changes in the applied technology, the need for introducing better work organization);

- Issues related to the market function (competition, the increased needs of the consumers, the increase of foreign competition, disloyal competition, improving the product and service quality);

- Systemic issues (unemployment, ownership relations, and change in social relations).

Those reasons raised the issue for introducing organizational changes in different spheres of the enterprise function. In summary, the managers believe that changes need to happen in the enterprise objectives, employees, organizational culture, organizational technology and organizational structure, after which they believe Macedonian enterprises will be competitive with the foreign ones at the domestic market as well as at the international market.

\section{DESIGNING A MODERN ORGANIZATIONAL STRUCTURE FOR THE ENTERPRISES IN THE ECONOMY OF THE REPUBLIC OF MACEDONIA}

The ideal of each enterprise is creating an organizational model that will allow the enterprise to successfully face and resolve the complex problems during its operation. Instead of the old strategy to be the best at everything, now there comes a new strategy which finds a relation between the competitive advantage of the enterprise with a more effective completion of smaller number of activities. In other words, a strategy of competence, openness and cooperation and collaboration with other enterprises is suggested. That means that the enterprise should focus on the activities that it accomplishes the best and disregard all those activities that other enterprises do faster, more efficient and cheaper.

The new forms of designing an organization set the enterprise on a path that leads to a flexible, decentralized and innovative organization. Innovative activities related to cooperation with external factors, provide space for outsourcing of business possibilities and resources which are not available inside organization (Bobera at al, 2017, p. 1). An important trait of those organizations is the modification of the enterprise into a "shallow organization" with a small number of hierarchical levels and wide span of control, based on the use of the information technology. In that manner, the organization becomes more and more democratic since the decisions in the "shallow organizations" are made and executed much 
faster compared to the models with a hierarchical structure. In the same time, that means a transformation of the organization from a vertical to a horizontal organization. A horizontal organization does not have a traditional hierarchy, but teams of experts responsible for the completion of certain tasks.

The results from the questionnaire impose the need for additional efforts in creating that type of organizational structure, one that will allow for effective and efficient operation. Moreover, the objective factors as well as the subjective factors which can assist in that process have to be taken into account.

A second segment in the design of the organizational structure, which has been proven with the conducted survey, is the vast number of specific characteristics between the different forms of enterprises. Having those reasons in mind, we believe that creating an efficient and effective organizational model is a complicated and delicate process where we have to use the knowledge from the theory, the acquired work experience and the specific characteristics of the enterprise itself. Parallel to that, the operation of the economic system on micro level as well as on macro level has to be respected.

If we conduct a quality and quantity analysis of both the theoretical part and the questionnaire for the managers in the economy of the Republic of Macedonia, we believe that we can define the issues the resolution of which will allow the designing of an appropriate form of organizational structure that will provide for effective and efficient enterprise operation. Those issues are the following:

1. How to design the organizational units within the enterprise?

2. How to organize and execute the process of organizational changeswith some problems (see more in Burnes, 2015; Gerbec, 2017).

The data gathered with the questionnaire, after its processing, analysing and quantification, has provided relevant conclusions on the implementation of the different forms of organizational design in the enterprises in the economy of the Republic of Macedonia in practice. Furthermore, we are free to conclude that the said implementation and the function of the organizational design in the enterprises in the economy of the Republic of Macedonia, in comparison with the modern theory for organization, are similar in the following aspects:

- The dependence of the applied form of organizational structure on the nature of its surroundings;

- $\quad$ The dependence of the applied degree of specialization on the applied form of organizational structure;

- The effect of the span of management over the decision-making system. However, the survey pinpointed issues related to the design of the organizational units, where, in our opinion, certain corrections need to be 
Parameters of organizational structure in enterprises in the Republic of Maced...

made in order to provide for more efficient and more effective enterprise operation. One of those segments that we believe managers should pay special attention to and show interest is the application of information technology in the designing and functioning of the enterprises, a tool that is not utilized sufficiently.

\section{THE ROLE OF THE INFORMATION TECHNOLOGY IN DESIGNING A MODERN ORGANIZATIONAL STRUCTURE FOR THE ENTERPRISES IN THE ECONOMY OF THE REPUBLIC OF MACEDONIA}

One of the characteristics of the modern age is the use of the information technology. This is an inevitability that managers must take into account. Not using the modern working tools will render the enterprise uncompetitive and will easily push it aside from the market. That has to be taken into consideration when designing an organizational structure i.e. the extent of the information technology used and its application in the enterprise operation.

The form of the design of the future is the e-enterprise (Behrooz \& Ghasemi, 2015). The possibilities the internet provides are huge. In that respect the traditional organizational structures are replaced with new ones where the basis for their organization will be the applied information technology.

The information technology with the assistance of the telecommunications mitigates the process of creating network of organizations and even leads to eliminating the lines between the organizations. The modern organizations possess the know-how which alongside the information becomes the basic resource of the organizations. The modern organizations are also organizations that learn, organizations that continuously adapt to the changes.

Within this framework, a special emphasis deserves to be put on the effect the information technology has on the following areas of enterprise operation:

- It makes the production processes more flexible and consequentially enables the organizations to adapt quickly to the changes in the surroundings;

- The changes that the informational technology dictates in the managing process are evident: big number of managers, analysts and other expert employees, especially from the middle level of management organization, are pushed aside from production and transferred to the other phases of operation (preparation, planning, and control).

- The information technologies decrease the differences in the structures between small, medium and big enterprises, between centralized and 
decentralized organization. Therefore, they provide the big enterprises with the flexibility that small enterprises have, applying decentralized decision-making in a centralized organization, and on the other hand they provide a central monitoring and control to a decentralized organization.

Nevertheless, we must also name the potential obstacles for an extensive application of computers (Derek \& Hall, 2004, p. 143.):

- Problems with unsuitable access;

- System that does not operate in real-time;

- System that does not provide online research;

- System that does not provide flexible research.

In addition, utilizing the information technology causes the decrease in number of employees. This is due to the substitution of people with machines on positions that used to be occupied by human workforce in the past. But, beside the application of information technology, overemployment also arises as a result from the shift in the behavioral culture i.e. the replacement of the system job for everyone with employment on the basis of profit, the processes of globalization and elimination of borders between markets at domestic level as well as at international level.

The result of decreasing the number of employees is overemployment. It poses a social problem which is quite difficult to solve properly. Now the organizers are faced with the task of finding the solution to the essential issue: creating such a form of organizational structure that will satisfy all the parties, the owners of the capital, managers and employees.

Of course, it is difficult to reach a solution whereby its application will satisfy all the interested parties. Because of those reasons, a solution will be put forward depending on what is critical in the given moment.

For that reason, a form of organizational structure has to be designed that will solve the issue of the excess employees that become useless and purposeless in the most reasonable manner. New organizational segments must be created that will engage them i.e. expanding the operations, conquering new markets, diversifying the activities and the production.

\section{CONCLUSION}

Understanding the organizations, especially those in the area of economy (enterprises), their principles and the rules of their operation is necessary. That necessity is particularly stressed with managers that run the enterprises. According to that, the managers are the prime users of the knowledge on the enterprises. 
Parameters of organizational structure in enterprises in the Republic of Maced...

Aware of the gravity and the complexity of the tasks set by the research object, we believe that only the symbiosis of the results from the theoretical research on organizational design and the effects of their application in our organizational practice can contribute to a selection of an adequate organizational model which can be used as a powerful organizational tool by the managers, one that has important effect on achieving the set objectives.

We especially point out the assumptions that must be taken into account and implemented faithfully if we want to bring about appropriate changes in the organizational structure of our enterprises. Those assumptions are related to the connection between the applied model of organizational structure and the nature of the surroundings, the connection between the work specialization and the applied form of organizational structure, the interdependency of the span of management and the decision-making system, as well as the conditions for organizing and executing organizational changes.

After receiving the responses and processing them, we have noted that the following assumptions can be accepted with a high percentage of satisfaction:

- $\quad$ There is $99 \%$ accuracy of the hypothesis that the enterprises with applied functional organizational structure work in conditions of stable, simple or homogenous surrounding, while those with divisional organizational structure work in conditions of unstable, complex or heterogeneous surrounding;

- $\quad$ There is $95 \%$ accuracy of the hypothesis that there is a relation between the work specialization and the applied form of organizational structure;

- $\quad$ There is $99 \%$ accuracy of the hypothesis that there is an interdependence between the span of control and the decision-making system.

Nonetheless, despite accepting the set hypotheses whereby we show that the organizational design of the enterprises in the economy of the Republic of Macedonia is identical with what we have proven in the theoretical part, there are still some segments that need to be corrected in order to provide for an efficient and effective enterprise operation.

Our opinion is that the managers should adapt to the organizational changes caused by the market as well as to the factors and the parameters that design the organizational structure. Furthermore, they should include all of the rest of the employees in those activities so that they can provide optimization of the effectivity and the efficiency of the organizational structure as a whole. The presence of obstacles while planning the execution of the organizational changes is normal, where the main opposition are the employees. That stems from fear of 
organizational changes, insecurity, threats to the social relations, aversion towards control, economic factors etc.

\section{LITERATURE}

1. Arif, M., Zahid, S., Kashif, U., \& Sindhu, M. I. (2017). Role of leader-member exchange relationship in organizational change management: Mediating role of organizational culture, International Journal of Organizational Leadership, 6(1), 32-41.

2. Armstrong, M. (2016). Management Processes and Functions, fourth edition. London: Institute of Personnel Management,.

3. Basurto, L. (2017). Book Review: Implementing Positive Organizational change: A Strategic Project Management Approach, PM World Journal, 6(7), 1-3.

4. Behrooz, R., \& Ghasemi H. M. (2015). Designing a model of organizational agility: A case study of Ardabil Gas Company, International Journal of Organizational Leadership, 4(2), 100-117.

5. Bobera, D., Leković, B., \& Strugar-Jelača, M. (2017). Coopetition as an external source for driving innovation: research findings from Ap Vojvodina, Економски погледи, 19(1), 1-16

6. Burnes, B. (2015). Understanding Resistance to Change Building on Coch and French, Journal of Change Management, 15(2), 92-116

7. Derek, T., \& Hall, L. (2004). Personnel Management- HRM in Action ( $3^{\text {rd }}$ edition). London: Prentice Hall, Hertfordshire.

8. Gerbec, M. (2017). Safety change management - A new method for integrated management of organizational and technical changes, Safety Science, 100(Part B - December), 225-234.

9. Gill, C., \& Kleiner, B.H. (2018). Case studies in organizational change, Industrial Management, 60, (2), 27-30.

10. Giurge, L. M., Van Dijke, M., \& Xue Z. (2015). Timeliness: How Span of Control Facilitates Timely Decision-Making, Academy of Management Annual Meeting Proceedings, 2015(1), 1-1. https://doi.org/10.5465/ambpp.2015.16484abstract

11. Fang, S.C., \& Chen, H.K. (2016). Strategic intent, organizational environment, and organizational learning mechanisms, Personnel Review, 45, (5), 928-946.

12. Faritovna, P.L. (2014). The Assessment Of Influence Of Enterprise External Environment On Its Organizational Structure, Science Journal of Volgograd State University. Global Economic System /Vestnik Volgogradskogo Gosudarstvennogo Universiteta. Seriâ 3, Èkonomika, Èkologiâ, 25(2), 54-61. 
13. Micić, R. (2015). Characteristics of Environment And Their Influence On Organization Structuring, Management \& Education / Upravlenie i Obrazovanie, 11, 7-12.

14. Ortín-Ángel, P., \& Salas, V. (2002). Compensation and Span of Control in Hierarchical Organizations. Journal of Labor Economics, 20(4), 848-876.

15. Pushpa, A. (2014). Effect of Uncertain and Turbulent Environment on Organizational Design, Economics \& Business Journal: Inquiries \& Perspectives, 5(11), 11-24.

16. Rauh, M.T. (2014). Incentives, wages, employment, and the division of labor in teams, RAND Journal of Economics, 45(3), 533-552.

17. Smollan, R.K. (2017). Supporting staff through stressful organizational change, Human Resource Development International, 20(4), 282-304. 